\title{
In-Situ Synthesis and Characterization of Schiff base [Zn(Anil-oPD)4] Metal Complex
}

\author{
Pandian Paulraj, Madasamy Kumar, Arumugam Sathamraja, Govindaswamy, Ayyar Manikandan
}

\begin{abstract}
The insitu synthesis of Schiff base metal complex using o-phenylenediamine (oPD) and p-anisaldehyde (p-anisal) as starting materials with Nickel nitrate hexahydrate ( $\mathrm{Zn}(\mathrm{NO3}) 2.6 \mathrm{H} 2 \mathrm{O})$ as a metal precursor in equimolar ratio (1:1:1 M) at room temperature. After the reaction time, the prepared metal complex washed several times with ethanol and boiled water for complete removal of un-reacted starting materials. The following characterization was used to confirm the metal complex by $U V$-visible spectroscopy (UV-Vis.), Fourier Transforms-Infrared spectroscopy (FT-IR), X-ray diffraction pattern (XRD) and Cyclic Voltammetry $(C V)$.
\end{abstract}

Keywords: Schiff base, Metal complexes, Insitu method, cyclic voltammetry

\section{INTRODUCTION}

The most of the schiff base and its metal complexes are synthesized using condensation reaction, which are having the $\mathrm{C}=\mathrm{N}$ functional group in it and which are synthesized usually by the reaction of amine and aldehyde $[1,2]$. For the past few decades, these kind of metal complexes play a vital role in various fields such as pharmacy companies, life sciences, chemical science especially inorganic and analytical field and also medical industries and it has display a broad range of utilization in various fields like antitumor, antibacterial and antifungal activity[3-8]. The presence of bulkier group in its structure having the steric hindrance and its stabilization of complexes by its metal oxidation state and it has very good solubility for the further spectral analysis to confirm the formation of metal complex [9-15]. In this present investigation, aniline based amines were used for the formation of ligand with easily reacted aldehyde and it's for metal complexes, the corresponding metal precursor is used with amine and aldehyde and especially the insitu approaches followed for the synthesis of metal complexes $[16,17]$. This approach has various benefits especially friendly approach to our environmental, cost effect with atom economy, less hazardous nature. Generally, the formation of schiff base ligand by the reaction of aromatic amine with carbonyl compound (aldehyde) via hemiaminal followed by

Revised Manuscript Received on July 22, 2019

Pandian Paulraj, Assistant Professor, Department Of Science \& Humanities, Bharath Institute Of Higher Education And Research TamilNadu,India.Email: paulrajp.che@bharathuniv.ac.in

Madasamy Kumar,, Department Of Science \& Humanities, Bharath Institute Of Higher Education And Research TamilNadu,India

.Email: kmrorg@gmail.com

Arumugam Sathamraja Department Of Science \& Humanities, Bharath Institute Of Higher Education And Research TamilNadu,India.Email: sathamrajaarumugam@gmail.com

Govindaswamy Padmapriya Department Of Science \& Humanities, Bharath Institute Of Higher Education And Research TamilNadu,India .Email: ppstminex@gmail.com

Ayyar Manikandan Department Of Science \& Humanities, Bharath Institute Of Higher Education And Research TamilNadu,India.Email mkavath15@gmail.com the imines formation through nucleophilic addition reaction [18-27].

\section{EXPERIMENTAL METHOD AND TECHNIQUES}

\section{A. Chemicals}

The analar grade reagents only uses as received in this work for the synthesis. The high purity salts of $p$-toluedine, $p$-Anisaldehyde, Methanol, Ethanol, Zinc nitrate, Copper nitrate, Nickel nitrate were purchased from Fluka, Lancaster Chemical company.

\section{B. Instrumentation}

The information of the stability and structures of the materials can be discovering by UV-vis. spectrophotometer. The spectra was recorded with C-driven model UV-1800 (Shimadzu), Japan spectrophotometer (resolution $0.1 \mathrm{~nm}$ ). FT-IR is one of the very important tool to find what are the functional groups are present in the molecules and modification on the metal surfaces (coating), which is used to prevent the growth of the nanoparticles by aggregation as well as the surface phenomenon of the inorganic metal nanoparticles. The FT-IR spectrophotometer for the analysis of the samples in Perkin-Elmer, USA Y-40 model within the range of $400-4000 \mathrm{~cm}-1$. All spectra were correct with reference background spectrum of $\mathrm{KBr}$. XRD pattern taken with a Philips instrument (JSO Debye Flex 2002 Seifert) at a $10^{\circ} / \mathrm{min}$ scanning speed from $10^{\circ}$ to $80^{\circ}$. And its electrochemical measurements are carrying out using a CHI-660A (CHI Instruments Co. USA) electrochemical workstation. All the solutions were prepared for the electrochemical investigation used to purged the N2 gas for 10 minutes before the stating the analysis

\section{RESULT \& DISCUSSION}

\section{A. Synthesis of ligand}

The Schiff base ligand was synthesized using $1.07 \mathrm{~g}$ of $o$-phenylenediamine and $1 \mathrm{ml}$ of $p$-anisaldehyde in methanol was allowed to stirred $5 \mathrm{~h}$ in inert atmosphere. A white precipitate obtained after 15 minutes, it confirms the formation of ligand successively in this methods and collected the white precipitate and washed with methanol using copious amount until the complete removal of un-reacted monomers and dried in vacuum 

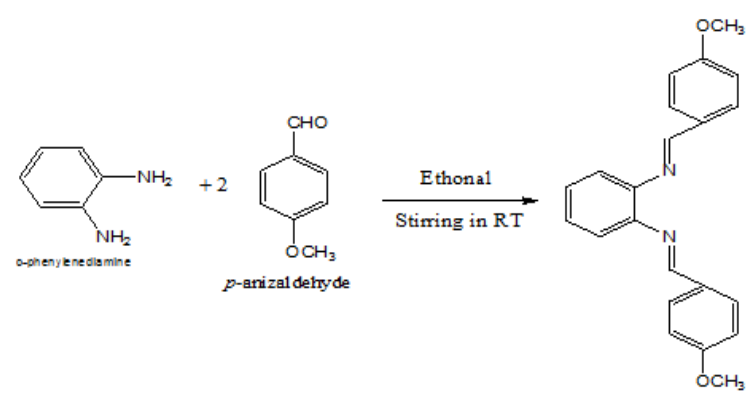

\section{Scheme 1: In-situ synthesis of Schiff base [Anil-oPD] ligand}

\section{B. Synthesis of Zinc complex}

The Schiff base Zinc metal complex was synthesized by using $1.07 \mathrm{~g}$ of $o$-phenylenediamine and $1.20 \mathrm{ml}$ of $p$-anisaldehyde were dissolved in ethanol separately. . The p-anisaldehyde added drop by drop wise in the stirred solution of $o$-phenylenediamine and permissible the reaction till 10 minutes and then the methanolic solution of $1.45 \mathrm{~g}$ of Zinc nitrate was added slowly till 10 minutes and then the reaction was allowed $5 \mathrm{hr}$. A light white coloured precipitate was formed which is confirms the formation of metal complexes and collected the pale green precipitate and washed with methanol using copious amount till the complete removal of un-reacted monomers, metal precursor and dried in vacuum

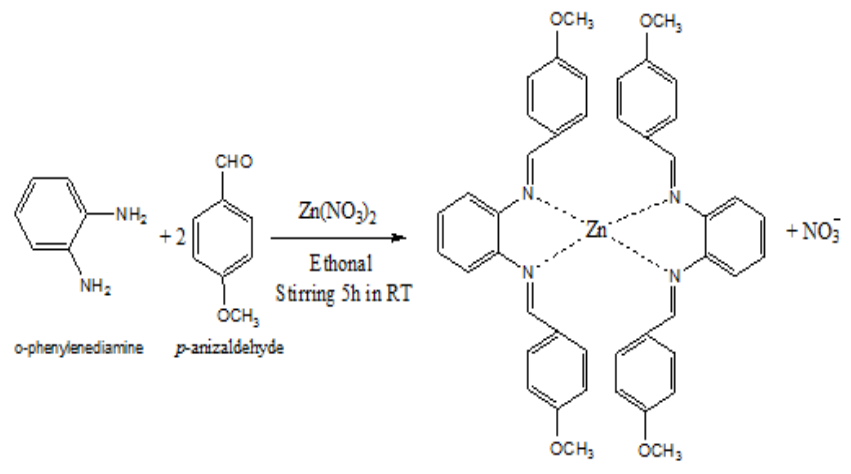

Scheme 2: In-situ synthesis of Schiff base [Zn(Anil-oPD $\left.)_{4}\right]$ ligand

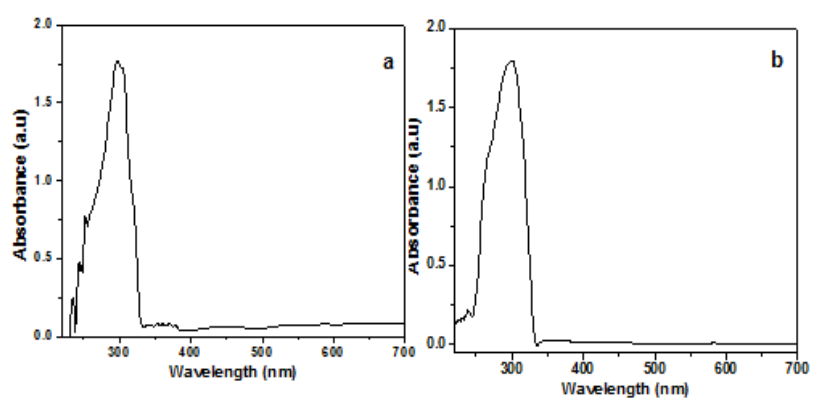

3.FT-IR spectral analysis

Figure 2 shows the FT-IR spectra of $\left[(\text { Anil-oPD })_{4}\right]$ (a) and $\left[\mathrm{Zn}(\text { Anil-oPD })_{4}\right]$ (b). The ligand has average intense peaks at 1249, 1610, and $1695 \mathrm{~cm}-1$ are for $v(\mathrm{C}-\mathrm{O}), v(\mathrm{C}=\mathrm{N})$ and
$v(\mathrm{C}=\mathrm{O})$, respectively. The response in the region of 540-590 $\mathrm{cm}-1$ and $470-500 \mathrm{~cm}-1$ are assigned to $v(\mathrm{M}-\mathrm{N})$ and $v(\mathrm{M}-\mathrm{O})$ stretching vibrations were conform the metal are strongly bound with ligand successively. The wide response between in 3149-3300 cm-1 observed the complex having hydrated by its broad response. The bands at $2800-3000 \mathrm{~cm}-1$ due to the stretching of $v(\mathrm{C}-\mathrm{H})$ and the band at $\sim 1598 \mathrm{~cm}-1$ due to the stretching vibration of $v(\mathrm{C}=\mathrm{C})$ and the responses of aldehyde $v(\mathrm{C}-\mathrm{H})$ obtained at $1309 \mathrm{~cm}-1$. Some of the bands of metal complexes are observed at slightly lower region compared with pure ligand, which confirms the metals were coordinated with Schiff base ligand.
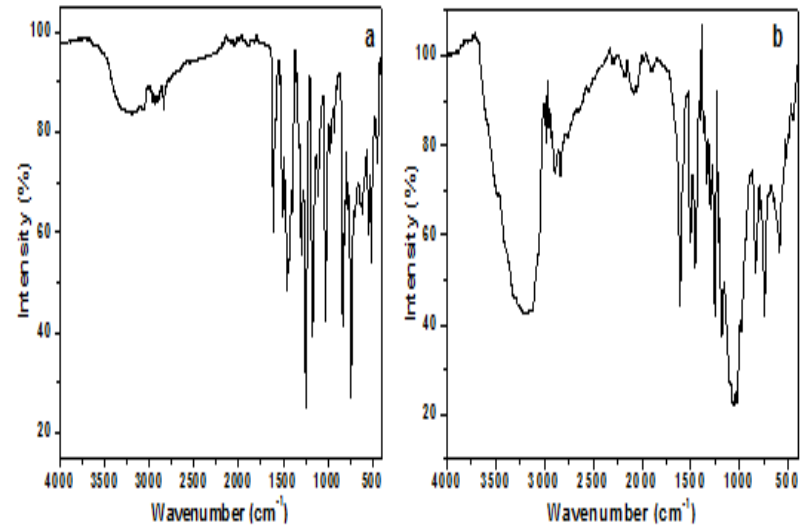

Fig.4 FT-IR spectra of Schiff base (a) and Schiff base Zinc complex (b).

\section{X-ray Diffraction studies}

Figure 3 shows the XRD spectra of [(Anil-oPD $\left.)_{4}\right]$ (a) and [Zn(Anil-oPD) $\left.)_{4}\right]$ (b). The spectrum 3(a) show some of the peaks at the region of $10-30^{\circ}$ is due to the conformation of the Schiff base ligands has amorphous nature but in the case of spectrum 3(b) has well aligned sharp peaks till $50^{\circ}$ is attributed to the presence of metal ion coordinated with the Schiff base ligands and also it has good crystalline nature. The prepared metal complexes having well crystalline sharp peak in its pattern due to its well crystalline nature and also it has considerable change in its pattern [22,23]. The grain nature and its size obtained using Scherre's formula using it's the value of full width half maximum peak value. By these spectra we can easily find out the nature of crystallinity of the metal complexes by the observation of the broad bands at $2 \theta=15-30$

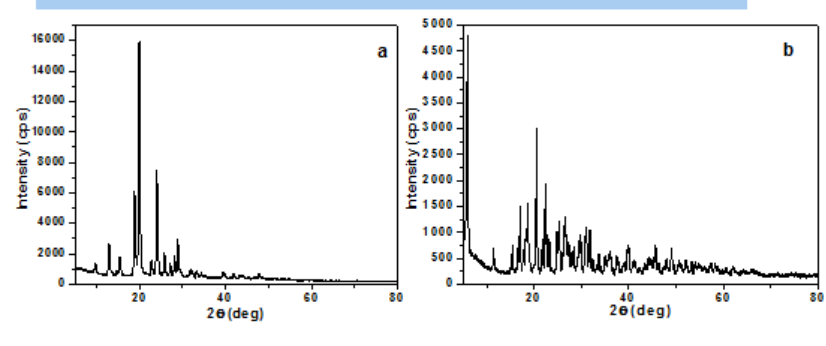

Fig.3. XRD spectra of [(Anil-QPD) 4 (a) and [Zn(Anil-QPD)4] (b).

Fig.4. XRD spectra of $\left[(\text { Anil-oPD })_{4}\right]$ (a) and [Zn(Anil-oPD $\left.)_{4}\right]$ (b).

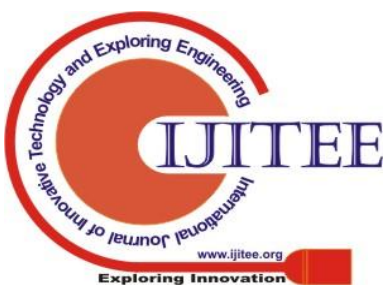


The modified electrode was prepared after polishing with alumina powder with washing with water, sample amount near $2 \mathrm{mg}$ of complex placed on micro slide and add few drop of methanol for making it wet and rub over the surface of GCE for adhering the metal complex on the GCE surface and dried well. All the solution were prepared with purity and purge with N2 air to remove the presence of oxygenated air making it fit for analysis before 10 minutes of measurements.

\section{Electrochemical responses of [Zn(Anil-oPD)4]}

Figure 4 shows the electrochemical responses of [Zn(Anil-oPD)4], which are (a) Zinc Schiff base ligands in $0.1 \mathrm{M}$ PBS (pH 6) at scan rate $50 \mathrm{mV}$. The metallic Schiff base complexes has strong peak at $-0.55 \mathrm{~V}$ and $+0.63 \mathrm{~V}$ due to its irreversible anodic responses of the one-electron oxidation for the bulk species. Two peaks, a irreversible but oxidation responses observed at $-0.03 \mathrm{~V}$ and $-0.47 \mathrm{~V}$ which is attributed for the oxidation state of the metal transfer in the complexes and it confirms the electrochemical nature of the reversibility of ligand. The one broad strong irreversible peak observed for the electron transfer in the ligand to metal

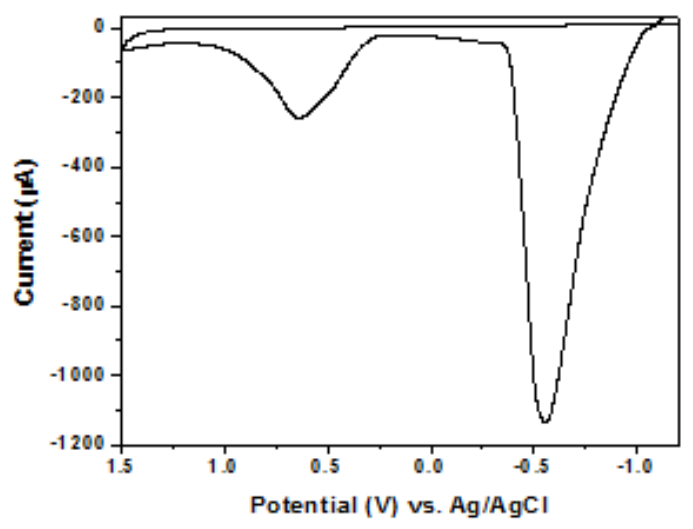

Fig.4. CV spectrum of [Zn(Anil-oPD)4] in 0.1 M PBS (pH 6) at scan rate $50 \mathrm{mV}$.

\section{CONCLUSION}

The developments of synthesizing new metal complexes have grown rapidly. The transition metal complexes have numerous applications in various fields. In this present investigation, we successively synthesized the Schiff base zinc metal complexes using in-situ method in room temperature. For the ligand preparation $p$-anizaldehyde and $p$-toluidine was used as monomer and nitrate salt of $\mathrm{Zn}\left(\mathrm{NO}_{3}\right)_{2} \cdot 6 \mathrm{H}_{2} \mathrm{O}$ is used as metal precursor. To confirm the formation of ligand and its complexes by some spectral studies which are UV-Vis, FT-IR, XRD and CV, which are confirms the metal are present in the complex.

\section{REFERENCES}

1. I. Dilovic, M. Rubcic, V. Vrdoljak, S.K. Pavelic, M. Kralj, I. Piantanida, M. Cindric, Bioorg. Med. Chem. 16 (2008) 5189.

2. A. Jarrahpour, M. Motamedifar, K. Pakshir, N. Hadi, M. Zarei, Molecules 9 (2004) 815.

3. P. Bhavani, A. Manikandan, P. Paulraj, A. Dinesh, M. Durka, S. Arul Antony, J. Nanosci. Nanotechnol. 18 (2018) 4072-4081

4. Kumar M, Sribalan R, and Padmini* V, Chemistry Select, 2016, 1, $1-6$.

5. P.H. Wang, J.G. Keck, E.J. Lien, M.M.C. Lai, J. Med. Chem. 33 (1990) 608 .
6. P. Paulraj, N. Janaki, S. Sandhya, K. Pandian, Colloids and Surfaces A: Physicochem. Eng. Aspects 377 (2011) 28-34

7. Kumar M, Padmini V*, Ponnuvel K, J.Saudi Chem. Soc, (2014): http:// dx.doi.org/ 10.1016/ j.jscs.2014.03.006

8. A. Das, M.D. Trousdale, S. Ren, E.J. Lien, Antiviral Res. 44 (1999) 201

9. P. Paulraj, A. Manikandan, E. Manikandan, K. Pandian, M. K. Moodley, K. Roro, K. Murugan, J. Nanosci. Nanotechnol. 18 (2018) 3991-3999.

10. R. Mladenova, M. Ignatova, N. Manolova, T. Petrova, I. Rashkov, Eur Polym. J. 38 (2002) 989.

11. Kumar M, Padmini V*, Bhuvanesh N, Res. Chem. Intermediates., 2017, 8, 4517-4530.

12. O.M. Walsh, M.J. Meegan, R.M. Prendergast, T.A. Nakib, Eur. J. Med.Chem. 31 (1996) 989.

13. K. Kaviyarasu, E. Manikandan, P. Paulraj, S. B. Mohamed, J. Kennedy, J. Alloys Compd.593 (2014) 67-70.

14. G. Ceyhana, S. Urus, I. Demirtas, M. Elmastas, M. Tumera, Spectrochim. Acta. A. 81 (2011) 184.

15. F. Ragaini, Dalton Trans. 2009, 2009, 6251-6266. 71

16. Y.c. Liu, Z.y. Yang, J. Organomet. Chem. 694 (2009) 3091.

17. B.K. Santra, P.A.N. Reddy, G. Neelakanta, S. Mahadevan, M. Nethaji, A.R. Chakravarty, J. Inorg. Biochem. 89 (2002) 191

18. Ponnuvel K, Kumar M, Padmini V*, Sensors and Actuators B: chemical, 2016, 227, 242-247.

19. D. de Bellefeuille, M.S. Askari, B. Lassalle-Kaiser, Y. Journaux, A Aukauloo, M. Orio, F. Thomas, X. Ottenwaelder, Inorg. Chem. 51 (2012) 12796.

20. V. S. V. Satyanarayana, P. Sreevani, A. Sivakumar, V. Vijayakumar, Arkivoc 2008, 221-233 (2008).

21. V. Patel, P. Trivedi, , H. Gohel, D. Khetani, Int. J. Adv. Pharmacy, Biol. Chem. 3, 999-1003 (2014).

22. R. Marx Nirmal, P. Paulraj, K. Pandian, K. Sivakumar, AIP Conf. Proc. 1391(2011) 597-599

23. M. A. Ashraf, K. Mahmood, A. Wajid, M. J. Maah, I. Yusoff, Int. Conf. Chem. adn Chem. Process 10, 1-7 (2011).

24. D.J. Díaz, A. K. Darko, L. McElwee-White, Eur. J. Org. Chem. 2007, 4453-4465. 70.

25. B. Gabriele, R. Mancuso, G. Salerno, Eur. J. Org. Chem. 2012, 6825-6839.

26. E. Prabakaran, S. Parani, M. Alexander, P. Paulraj, K. Pandian, J Nanosci. Lett. 3 (2013) 1-9.

27. N. R. Bader, RASAYAN J. Chem. 3, 660-670 (2010),

\section{AUTHORS PROFILE}

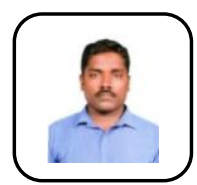

Pandian Paulraj, Associate Professor, Department Of Science \& Humanities, Bharath Institute Of Higher Education And Research TamilNadu,India

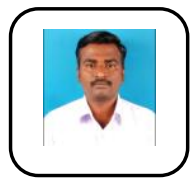

Madasamy Kumar, Associate Professor Departmen Of Science \& Humanities, Bharath Institute Of Higher Education And Research TamilNadu,India

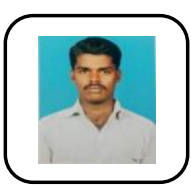

Arumugam Sathamraja Lab Instructor Department Of Science \& Humanities, Bharath Institute Of Higher Education And Research TamilNadu,India

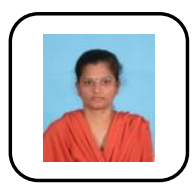

Govindaswamy Padmapriya Associate Professor Department Of Science \& Humanities, Bharath Institute Of Higher Education And Research TamilNadu,India

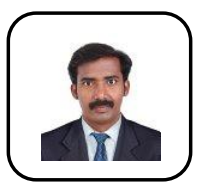

Ayyar Manikandan Associate Professor Department Of Science \& Humanities, Bharath Institute Of Higher Education And Research TamilNadu,India 